\title{
THE IMPACT OF STUDENT RESPONSE SYSTEMS ON STUDENT BEHAVIOR AND PERFORMANCE IN A MANAGEMENT INFORMATION SYSTEMS COURSE
}

Lisa Z. Bain, Rhode Island College, lbain@ ric.edu

Jane Przybyla, Rhode Island College, jprzybyla@ ric.edu

\begin{abstract}
Student Response Systems are an instructional technology that allows instructors to display questions on a screen in the classroom and students to respond using a handheld device called a clicker. There are numerous academic research studies and surveys documenting the benefits in terms of student enjoyment, interest, attendance, participation, comprehension, and preparation. This research study conducted a survey asking students their perceptions of how Student Response Systems influenced their behavior inside and outside of the classroom. In addition to the survey, student performance was analyzed by comparing the final grades in two semesters of a Management Information Systems course, one in which clickers were used and one in which clickers were not used. Most students agreed that clickers increased their interest during class, helped them understand the material, encouraged them to listen, and helped them prepare for exams. Students overwhelmingly enjoyed using the clickers but not all aspects of their use. There were mixed opinions about several features of the system and the students did not necessarily agree that clickers encourage some of the behaviors preferred by instructors. However, student performance significantly increased during the semester with clickers compared to the semester without clickers. Instructors should carefully examine their teaching style and the nature of the course before using a Student Response System. There are many, positive and proven reasons to use clickers, but instructors need to carefully plan the implementation and incorporate the desired benefits into their course.
\end{abstract}

Keywords: Student Response Systems, Clickers, Active learning, Instructional technology

\section{INTRODUCTION}

The art of teaching uses many forms, methods, and techniques, all with the goal of guiding the student through the learning process. One of which, and perhaps the most common, consists of instructors

Volume X, No. 1, 2009 discussing some type of material in a classroom setting then asking students a series of questions pertaining to that material. The instructor asks a question, the students respond, and the class discusses the answer or answers. This is a typical day in just about any classroom or place of learning. Student Response Systems, more commonly referred to as clickers, add a new dimension to this scenario allowing instructors to display the questions on a screen with computer projection while the students answer using a hand-held device, usually called a clicker. The instructor can then display the results for the class as a whole and identify the correct answer to the question. The results provide immediate feedback to the instructor and the student, identifying both student comprehension and attention. The clicker questions also offer an opportunity for class discussion or peer instruction depending on the students' answers and the instructor's preferences.

Although the main use of Student Response Systems is for displaying questions on a screen, instructors can use them for other instructional needs as well. Instructors can assign points for just answering the questions or answering the questions correctly. The system records this data by individual student for attendance and participation scoring. Instructors can deliver the questions throughout the class period to encourage participation or all at once for assessment purposes. This allows for pre- and post-lecture quizzing or other types of graded assignments. In addition to the prepared questions, instructors can also conduct opinion polling or surveys at any time during any class session. Therefore, there is a wide range of capabilities and a variety of uses available by using clickers.

Educational institutions first implemented Student Response Systems in the early 1990s primarily in large, science-related classes [1]. Hundreds of colleges and universities currently use these systems across disciplines and in various class sizes [13]. Primary and secondary educators also use the systems, as well as business and industry $[17,10]$. The term clicker is generally well recognized and 
known for being associated with this environment. However, there are various names for these systems including Audience Response System (ARS), Electronic Voting Systems, Classroom Communication Systems (CCS), Classroom Response System (CRS), and Personal Response System (PRS) [3, 18, 1, 6, 2] . This paper refers to the clicker environment as Student Response Systems.

\section{Components of Student Response Systems}

The components of a Student Response System consist of a receiver, an input device (clicker), and software. The system requires either an electronic classroom or a facility providing computer projection. The receiver is a small, hardware device that connects to a personal computer and receives the data from the clickers. In most cases, the receiver connects to the personal computer using the USB port. Instructors may have their own receiver and bring it with them to class or the institution may place the receiver in the classroom. In order to capture the data (votes) from the input devices, the receiver uses either infrared (IR) or radio frequency (RF) wireless signals. The trend is towards the RF signals due to increased speed, reliability, and distance [18]. The wireless capabilities may be one of the reasons for the system's recent popularity and use. The first Student Response Systems in the early 1990s required special hard-wired installations in each classroom [1]. Most current systems have the receivers as part of an instructor's kit that also includes the software.

The input device, or clicker, is a hand-held device that has buttons for answering the questions displayed on the screen. Students use the clicker like a TV remote control, press buttons to answer the questions, and the receiver at the front of the classroom receives the signals. The clickers vary by size, in the types of buttons, and capabilities. Some are very similar in size to a TV remote control while others are as small as a credit card. The buttons may support letters only (A, B, C, D, E), numbers only (09), or a combination of the two $(\mathrm{A} / 0, \mathrm{~B} / 1, \mathrm{C} / 2, \mathrm{D} / 3$, $\mathrm{E} / 0$ ). The more recent systems allow for a variety of input devices like laptops, PDAs, and cell phones [1]. However, most current systems are still proprietary and require all three components from the same vendor. The capabilities range from a few simple indicator lights to confidence levels of the answer [18]. The clickers have a unique ID number that allows the instructor, through the clicker software, to register it to a particular student. Students may be required to purchase the input devices individually or some institutions provide the input devices to the student.

The software runs on a personal computer or flash drive, which controls the receiver, runs the application programs, and captures and stores the data. The software provides settings that instructors may use to select preferences for items, such as student registration and question scoring. During class sessions, a number of items appear on the screen when the instructor opens the program. This display can include the time allotted for the question, the number of responses received, acknowledgement of the response, and other various features. During each clicker question, the software captures the responses from each input device and stores the data by student and by class session. It also provides the capability for the instructor to display the results from each clicker question, typically in the form of a histogram. This shows the percentage and count of each possible answer. The software also allows the instructor to indicate the correct answer on the screen for classroom viewing. Last, the clicker software provides programs for reporting student, question, and class results. Instructors typically view these outside of class for evaluation and grading purposes. In most cases, the clicker software is separate from the clicker questions. Instructors need to prepare the clicker questions in a presentation or word processing program, such as Microsoft PowerPoint or Word.

\section{Benefits of Student Response Systems}

Like any type of new instructional technology or teaching method, there is the issue of training and additional preparation time for instructors. The instructor must invest the time and effort to identify, select, and create clicker questions that are appropriate and useful in the classroom in addition to learning how to use the clicker software and receiver. Depending on the skill level of the instructor, this could take just hours or several weeks [1]. They also have to modify their course materials to accommodate the clicker questions, including the syllabus, grading and attendance policies, lectures, quizzes, and exams [11]. In addition, there will be time required on a regular basis to review the clicker reports, adjust the settings, and address technical issues. Why would instructors take the time to incorporate this into their classroom? Student Response Systems have the potential to provide many 
benefits to both instructors and students if implemented correctly. There are numerous academic research studies and surveys documenting these benefits in the classroom. Although the terminology varies, most documentation on clickers focuses on the areas of student enjoyment, interest, attendance, participation, comprehension, and preparation.

$\underline{\text { Student Enjoyment and Interest }}$

Current students are part of a generation that enjoys and regularly uses technology. It is an essential part of their everyday lives, inside and outside of the academic setting [16]. The students of today grew up playing video games and using personal computers. Technology is a normal part of their learning process and generally comes easy to them. One of the most common and prevalent benefits of Student Response Systems is student enjoyment. In a recent survey, $88 \%$ of the students agreed they enjoyed using the clickers [3]. Yes, most people would enjoy participating in a Jeopardy-like session. Using a clicker is similar to playing a game, which creates enjoyment for the student. Student Response Systems make this environment even better because each student gets to answer every question. The students have the opportunity to read a relatively short amount of text in the form of a question and select an answer in an anonymous and nonthreatening manner, seeing the results within seconds. The game concept also promotes active learning by getting the student involved with the course material in an entertaining way [15]. Since most students are comfortable with technology, they like using the clickers in this way. Simply put, clickers make the class fun [6]. The technology creates an atmosphere in the classroom that is similar to using a cellular phone and therefore, familiar and enjoyable to students. In addition, the design of the clickers is simple and straightforward, making them very easy to use [3]. Most instructors and students would agree that having an instructional tool that makes the class enjoyable is a benefit, but ultimately interest in the course material is essential for student learning. Students agree that using clickers increases their interest during class sessions [8]. Students know when instructors have clicker questions prepared for class sessions and therefore will show some interest in the lecture material and class discussions preceding the clicker questions. This helps students pay attention to the material and become more engaged in the class [5]. If students show more interest during class sessions, the hope is that this will increase their interest in the actual course material.

Student Attendance and Participation Making the class more enjoyable also influences student attendance and participation. Student Response Systems automate the attendance process by collecting and storing the data from each question answered by each student. If instructors incorporate the clickers into their grading system, there can be a positive affect on student attendance [4], [14]. This eliminates taking attendance at the beginning of each class session, tracking late arrivals, and monitoring students leaving before the class ends. The clicker software allows instructors to customize the settings for the points assigned for participation (simply answering) and performance (answering correctly). For example, a medium setting requires students to answer (click-in) at least $75 \%$ of the questions during that class session in order to receive their attendance points. The instructors can also give students additional points for answering the clicker questions correctly. Therefore, instructors have many options and may choose to poll or ask a question at the start of class to record attendance. Other instructors may choose to ask questions throughout the class and assign points based on participation and/or performance. Clickers provide a way for all students to participate in class, regardless of personality, background or skill level. Participation may come in the form of reading the clicker questions, asking questions, adding comments to discussions, and/or taking notes. Instructors using Student Response Systems report increases in the level of participation during class sessions [8]. Clickers provide a safe and easy medium for those who would not normally ask questions or participate in class discussions. There is a possibility that a student that continually answers the clicker questions correctly will have the confidence to start speaking in class. Likewise, a student who answers a clicker question incorrectly may ask a question in class as to why her answer was wrong. The clicker setting helps to create a more relaxed environment that encourages both types of participation [7]. One study found that for certain types of students, the participation level considerably increased [2]. Students benefit by participating in a class session, regardless of the type.

Student Comprehension and Preparation

In a traditional lecture, instructors have no tangible way of knowing if the students comprehend the material or are even listening during class sessions. 
Student Response Systems provide a measure of this by posing questions with an expectation of an immediate response. Some instructors use definition questions to identify basic comprehension, while others prefer more involved comprehension items or examples. The side effect of the clicker question/answer activity is the feedback the results provide. The students know right then whether they understood the material or not and so does the instructor. Other teaching tools have shown this type of feedback as beneficial to student learning [12]. The instructor can then reinforce the material, move on to the next topic, or use peer instruction. Having students discuss questions with other students improves their understanding and comprehension [1]. Students prefer peer discussion to other clicker uses, such as graded quizzes [9]. Instructors can also encourage students to reinforce material outside of class when they consistently answer questions incorrectly. Students may also request clarification or prepare in other ways. Many instructors revel at the thought of students preparing for class sessions by either reading the course material or textbook. If students prepare before or after class, then the chances of understanding the material should be higher. Instructors use a variety of methods to encourage student preparation, like assigned readings, quizzes, and homework assignments. Student Response Systems automate the quiz approach, simplifying the task of delivering and grading quizzes. Surveys have shown that students will prepare for class if they know they will be quizzed and the quiz is part of their grade [3]. Other studies show that students agree that clickers encourage them to prepare for class [19]. Student Response Systems can help students comprehend the course materials and encourage preparation.

\section{$\underline{\text { Research Questions }}$}

Student Response Systems have well-documented benefits in many academic areas. The research shows that large, science classes especially benefit from this type of instructional technology. In addition, smaller classes and other types of disciplines are now using clickers in the classroom with similar results. This paper examines the impact of Student Response Systems on student behavior and performance in four sections of a Management Information Systems course. The students completed a survey addressing the impact of the clickers on their behavior. In addition, the final grades from the Fall 2007 semester were compared to the final grades from the Fall 2008 semester to address the impact on student performance. The following research questions were addressed:

Student Behavior

1. What aspects of Student Response Systems impact student enjoyment?

2. What aspects of Student Response Systems impact student interest?

3. What aspects of Student Response Systems impact student participation?

4. What aspects of Student Response Systems impact student comprehension?

5. What aspects of Student Response Systems impact student preparation?

6. What aspects of Student Response Systems impact student attendance?

Student Performance

7. Does the use of clickers have an impact on student performance?

\section{METHODOLOGY}

\section{Background (College-Wide Clicker Standardization)}

After an increase in use and interest by faculty, the User Support Services (USS) Department at Rhode Island College (RIC) hosted three vendors of Student Response Systems for demonstrations in February 2008. The purpose was to allow faculty the chance to evaluate the different offerings in hopes of adopting one system for campus-wide use. This would prevent students from having to purchase more than one type of clicker and User Support Services from supporting multiple systems. It would also allow the college to provide the infrastructure support needed for these systems. The vendor demonstrations discussed the use of the systems, their respective capabilities, and the benefits. After multiple evaluations by USS and faculty, including several small pilots, USS selected the iClicker system in June of 2008 as the standard Student Response System for RIC. Beginning with the Fall 2008 semester, USS offers instructor kits to faculty, conducts training, and provides technical support for Student Response Systems as an instructional technology. In addition, students can purchase and re-sell the iClicker clickers directly from/to the campus bookstore. Based on this campus-wide adoption, the two faculty members responsible for teaching the Management Information Systems 
course in the School of Management decided to use clickers in all four sections for Fall 2008.

\section{Management Information Systems Course}

The Management Information Systems (MIS) course covers the fundamentals of analysis, design, and the implementation of information systems for managerial decision-making. The goal of this course is to present a core of IS principles with which every business student should be familiar and to offer a survey of the IS discipline that will enable all business students to understand the relationship of advanced courses to the curriculum as a whole. It also presents the changing role of the IS professional and shows the value of the discipline as an attractive field of specialization. The course uses primarily the lecture environment along with a variety of group and individual assignments, presentations, and exams. This junior level course is a core requirement for four out of the six business majors at this college. A typical composite of majors would consist of about 30\% Accounting Majors, 30\% Management Majors, 20\% Marketing Majors, 10\% Finance Majors, and $10 \%$ CIS Majors. Four sections of the course are run each semester, usually at overload capacity of 32 students. The MIS course was considered a good candidate for clickers for two reasons. First, the course covers a wide range of topics but each in minimal detail. Second, most students in the course are not CIS majors and are only taking the course only because it is required. Therefore, the interest level is not as high as it would be for a disciplinespecific course for a student at this level.

\section{Clicker Survey}

The clicker survey consists of a series of questions designed to ask students their perceptions of the benefits of Student Response Systems, in terms of their behaviors inside and outside of class. The instructors chose the six benefit areas of enjoyment, interest, attendance, participation, comprehension, and preparation and designed the survey to ask multiple questions about each benefit area. This would allow for more insight to the aspects of the system that impact student behaviors. In addition to the benefits, the instructors decided to ask the students a few basic questions about the clicker setup and question delivery. This resulted in a clicker survey with 7 topics and 30 questions. For example, the first question in the enjoyment topic is "I enjoy using the clicker to answer the questions." The clicker survey used a 5-point Likert scale for scoring, 5 for Strongly Agreed, 4 for Agreed, 3 for Neither Agreed or Disagreed, 2 for Disagreed, and 1 for Strongly Disagreed.

The instructors administered the clicker survey during the final two weeks of class using the Student Response System. This required approximately 20 minutes of class time. The results combined the answers to each question for all four sections of the course, removing student names. Although students' answers are anonymous during class sessions, the Student Response System software does store each individual answer by student name. As an added precaution, the instructors asked the students to swap clickers if they desired for additional anonymity.

\section{Student Performance}

In order to determine the impact of using a Student Response System on student performance, the instructors compared the final grades from the Fall 2007 semester (clickers not used) to the final grades of the Fall 2008 semester (clickers were used). The Fall 2007 semester had a similar composite of majors, the same four sections of the course, and the same instructors as the Fall 2008 semester. Each instructor calculated a final numerical grade to two decimal places for each student in all four sections for both semesters. The results section shows the calculations of the independent t-test for determining the following research hypothesis:

\section{$\mathrm{H}_{1}$ : Students using clickers in MIS during the Fall 2008 semester will have significantly higher final grades than students not using clickers in MIS during the Fall 2007 semester.}

\section{RESULTS}

Table 1 shows the results of the student survey including the mean, standard deviation, and median score for each question. It also shows a percentage for the students that voted Strongly Agreed/Agreed (SA/A), Neither Agreed or Disagreed $(\mathrm{N})$, and Strongly Disagreed/Disagreed (SD/D). The following sections describe each of these results.

<Insert Table 1 Here>

\section{Enjoyment and Interest}


The clicker survey included six questions about student enjoyment from using the Student Response Systems. As stated previously, the literature supports the fact that clickers increase student enjoyment and interest but does not necessarily identify the specific aspects. Most students enjoyed using the clickers (Mean 4.28, 83\%) and seeing the results after a question (Mean 4.43, 90\%). This was expected and not a surprising result based on the casual observance and student comments throughout the semester. It also supports other survey results and suggests that students are benefiting by having fun in the class. Student sentiment was favorable towards the options of showing the results during the answer period for a question (Mean 3.74, 62\%) and opinion polling (Mean 3.98, 67\%). Since instructors do not use these options in every class, there was no expectation as to the results. It does suggest that many students do enjoy these options but not all. About half of the students enjoyed reading the clicker questions (Mean $3.71,55 \%)$ and discussing the clicker questions (Mean 3.55, 46\%) with their classmates. This was lower than expected and showed that students do differentiate the use of the clickers with reading the material on the screen. It also suggests that not all students enjoy peer instruction. Again, instructors might not use peer instruction in every class session and may only use it when there is a comprehension or participation need. It may suggest that instructors need to use different techniques with peer instruction or gain more experience with its use.

The clicker survey asked two questions about student interest, one in the subject matter of the class and the other about interest during class sessions. Most students (Mean 4.20, 83\%) agreed that clickers increased their interest in the class session. Although this is supported by the literature, it was not expected and one of the positive surprises from the survey. This suggests that Student Response Systems can increase the level of interest in students during class. More than half of the students (Mean 3.88, 67\%) surveyed agreed that the use of the clickers increased their interest in the subject matter. Again, this was not expected of this course, where most of the students are not CIS majors. Although this is less than the enjoyment results, this is still considered a benefit in a service course like Management Information Systems.

\section{Attendance and Participation}

The clicker survey included five questions about student attendance in a class using a Student Response System. The questions asked not only about attendance but also about other factors of attendance. Most students (Mean, 4.12, 81\%) agreed that clickers encourage them to listen during class. This was higher than expected and showed an important benefit of Student Response Systems. This is similar to other surveys in the areas of student engagement and suggests a positive change in student behavior in class. The other factors of attendance also showed that a majority of the students agreed that clickers encourage them to attend (Mean 4.02, $67 \%$ ), be on time (Mean 3.83,61\%), stay for the entire class (Mean 3.92,64\%) and that the clickers should be used to record attendance (Mean 3.48, $55 \%$ ). The results of the other factors were lower than expected but did help in highlighting the listening factor. Again, the literature documents increases in student attendance in classes using clickers. The results of this survey suggest that clickers may not have a strong influence on all aspects of attendance but they do in the area of listening, which is still a positive and notable benefit.

The clicker survey consisted of four questions about student participation in a class using a Student Response System. Although the literature shows increases in student participation in classes using clickers, there are various types of participation. Many students (Mean 3.92, 76\%) agreed that instructors should use clickers for participation grades. This was somewhat surprising and could indicate that students believe they should get credit for using the clickers. This could vary widely depending upon whether the student purchases or the institution provides the clicker and whether the instructor uses the clickers as part of the course grading policy. Many students (Mean 3.57, 59\%) agreed that the use of clickers encourages them to take notes in class and participate in discussions (Mean 3.54, 51\%). This was higher than expected and is seen as a positive benefit suggesting an increase in class participation. Few students (Mean $3.09,28 \%$ ) agreed that clickers encourage them to ask questions in class. This result was lower than expected and did not support other surveys or instructor observances. It suggests there may be a difference in the way instructors use the clicker questions in the classroom. It could indicate that the clicker questions answered any students' questions about the class material or that the instructor answered the questions after displaying the results. 


\section{Comprehension and Preparation}

The clicker survey included two questions about student comprehension in a class using a Student Response System. Most students (Mean 4.24, 86\%) agreed that clicker questions help them understand the course material. This result was higher than expected and may be one of the most important student benefits of clickers. It also supports other surveys showing increased understanding of the course material and student performance. It suggests that clicker questions conducted in a class setting reinforces the lecture information and helps students grasp the content of the lecture. Students enjoy using the clicker, they show more interest in class, they listen more during class, and therefore have a better chance of understanding the material. Many students (Mean 3.55, 54\%) agreed that discussing the questions with their classmates helps in understanding the course material. This was lower than expected and had similar results to the question asking students if they enjoyed discussing questions with their classmates (Mean 3.55, 46\%). Other surveys reported higher results in this category. Again, this suggests that instructors may need to reevaluate or modify the execution of peer instruction.

The clicker survey consisted of four questions about student preparation in a class using a Student Response System. Two of the four questions resulted in higher than expected ratings and two resulted in lower than expected ratings, showing almost opposite behaviors in the students. Most students agreed that the clicker questions in class (Mean 4.38, 84\%) and the resulting study guides consisting of clicker questions (Mean 4.52, 84\%) helped them prepare for exams. This showed that students used both and suggests that students will use the clicker questions as part of their studying for exams and find them useful. However, this will vary by instructor and their type of exams. Few students agreed that the use of clickers encourages them to either prepare before (Mean 2.72, 27\%) or after class (Mean 2.79, 26\%). This was lower than expected and indicated that the use of a Student Response System did not encourage most students to read the course material. Many students did not enjoy reading the question and did not read before or after class. This suggests that reading is still an issue even in classes using clickers. However, clicker questions at least require the students to read the question and possible answers.

\section{Clicker Setup and Delivery}

In addition to the questions about student behavior, the clicker survey asked seven questions about the setup and delivery of the Student Response System. The results would give the instructors some idea about the basic implementation and use. Almost all of the students agreed that the registering process for the clicker was easy to complete (Mean 4.57, 95\%), the clicker was easy to use (Mean 4.85, 99\%), they could see the questions on the screen (Mean 4.88, $99 \%$ ), and they understand the questions (Mean 4.50, 94\%). This was expected but confirmed each item and allowed the instructors to maintain their current software settings. Most students (Mean 4.18, 82\%) agreed that they had time to read the question. This was expected but was lower than the other questions in this category. This suggests that instructors need to insure their settings match the type and length of questions and may need to customize the settings by class. A slight majority (Mean 3.46, 51\%) of the students agreed that they would like more questions per class. This suggests that the number of questions may be sufficient. This will vary by instructor and by class session. Less than half (Mean 3.02, 42\%) of the students agreed that clickers should be used for graded quizzes. This was actually higher than expected and may indicate that students do prefer credit for answering clicker questions in class. Again, this will vary by instructor. In fact, one of the two instructors in this study used graded quizzes more often. Most of the students $(82 \%)$ in that section agreed that clickers should be used for graded quizzes compared to $26 \%, 19 \%$, and $31 \%$ in the other three sections.

\section{Student Performance}

Numerous research studies and student surveys document the student benefits of Student Response Systems, but less information is currently available on student performance. This study compared the Fall 2007 final grades to the Fall 2008 final grades of four sections (about 100 students) of a Management Information Systems (CIS 352) course. The purpose was to determine if students using clickers in CIS 352 during the Fall 2008 semester will have significantly higher final grades than students not using clickers in CIS 352 during the Fall 2007 semester. This is a directional hypothesis. The t-test was used because there is one independent variable, two factors in the independent variable, one dependent variable, and quantitative data. The independent variable is the clicker use and the effect being the performance in terms of the students' final grades. The independent 
variable has two levels, the first that the Fall 2008 semester used clickers and the second that the Fall 2007 semester did not use clickers. The dependent variable is performance measured by the final grade of each student. The quantitative data consisted of numerical scores to two decimal places. The type of statistical test used was the independent t-test because the final grades for the students are not related. There is no connection between the students of the Fall 2008 and Fall 2007 semester. The results of the t-test showed the following:

\begin{tabular}{|c|c|c|}
\hline & $\begin{array}{l}\text { Number } \\
\text { in Group }\end{array}$ & Mean \\
\hline Grades - Fall08 (clickers) & 124 & 86.17 \\
\hline Grades - Fall07 (no clickers) & 120 & 82.59 \\
\hline
\end{tabular}

Levene Test $p$ value (Equal Variances Not Assumed) $p$ value less than $0.05(0.000916)$

1-tailed $p$ value

$p$ value less than $0.05(0.00049)$

The computed $p$ value (0.00049) was less than alpha (.05) so we rejected the null hypothesis. The final grades of the Fall 2008 semester are significantly higher than the final grades of the Fall 2007. The increase in student performance, in terms of the final grades, shows that performance is also a benefit of Student Response Systems.

\section{CONCLUSION}

This research study examined the impact of Student Response Systems on student behavior and student performance. Students completed a survey asking a series of questions about the most common benefits of clickers and the impact on their behavior. For student performance, instructors compared the final grades of students from a semester that did not use clickers to the final grades of students from a semester that did use clickers.

The clicker survey showed similar results to other surveys and supported many of the documented benefits of Student Response Systems. Most students agreed that they enjoy using the clicker, it increases their interest during class, it helped them understand the material, and it helps them prepare for exams. Surprisingly, students also agreed that clickers encourage them to listen in class and should be used for participation grades. Each of these benefits the students in many ways, inside and outside of the classroom. The clicker survey showed that students are mixed on many areas of the clickers as well. Only about half of the students enjoyed reading the questions or discussing the material with their peers. The use of clickers did not appear to have a strong impact on their attendance behaviors of being in class, being on time, and staying for the entire class or participation and note taking. In fact, only a small percentage of students agreed that the use of clickers encouraged them to ask questions or read the material before or after class. More research in these areas could highlight the best practices and techniques for peer instruction, participation, and preparation in the classroom. However, many students did agree that the use of clickers increased their interest in the subject matter of the course. Again, this is a service course to most business majors at this college. Instructors struggle with the low interest levels and the poor attitudes of non-CIS majors taking this course. Out of the 95 students that answered this question, 34 strongly agreed and 30 agreed. The instructors see this as a considerable benefit for this particular type of course. Most important, student performance significantly increased during the semester with clickers compared to the semester without clickers.

Student Response Systems have the potential to provide many benefits to the students in terms of their behavior and their overall performance in a course. The results of this study reinforced some of the well-documented benefits. It also provided more in-depth information on some of the more common benefits. Students do enjoy using the clickers but do not enjoy all aspects of their use. In addition, the clickers do not necessarily encourage some of the behaviors preferred by instructors. Instructors should carefully examine their teaching style and the nature of the course before using a Student Response System. It may not be the best fit for all instructors and for every class. The benefits are many to both instructors and students, but instructors must use the clickers in the appropriate way to realize these. Instructors need to carefully plan a clicker implementation and completely incorporate the desired benefits into their course.

\section{RECOMMENDATIONS}

There are two primary recommendations resulting from this research study, one based on the clicker survey and one based on the design of the student performance portion of the study. The first recommendation is to study the various ways instructors implement the clickers, primarily for 
grading. The results of the survey showed three areas of possible future research in peer instruction, student attendance, and student preparation. Each of these items showed potential for improvements in the use and/or implementation of the clickers by the instructor. This could be related to the technology or the way the instructor incorporates the technology in the classroom in terms of grading. For example, the use of graded quizzes may have a significant impact on student preparation. Likewise may be the case with student attendance.

The second recommendation addresses the limitations of the study in the area of student performance. This study used four sections of the same course, the same two instructors, and the same textbook. The grading components (assignments, exams, projects) were generally the same but not identical. In addition, the demographics and majors of the students were generally the same but not identical. The latter two items could impact the results of the student performance comparison. In future studies, this could be mitigated by using identical grading components and student population.

\section{REFERENCES}

1. Beatty, I. (2004). Transforming student learning with classroom communication systems. EDUCAUSE Center for Applied Research (ECAR) Research Bulletin, 2004(3), 1-13.

2. Beekes, w. (2006). The 'Millionaire' method for encouraging participation. Active Learning in Higher Education, 7(1), 25-36.

3. Caldwell, J. E. (2007). Clickers in the Large Classroom: Current Research and Best-Practice Tips. Life Sciences Education, 6(1), 9-20.

4. Carnevale, D. (2005). Run a Class Like a Game Show: 'Clickers' Keep Students Involved. Chronicle of Higher Education, 51(42), B3.

5. Cummings, R. G. \& Hsu, M. (2007). The Effects of Student Response Systems on Performance and Satisfaction: An Investigation In A Tax Accounting Class. Journal of College Teaching \& Learning, 4(12), 21-26.

6. Duncan, D. (2005). Clickers in the Classroom: How to Enhance Science Teaching Using Classroom Response Systems, New York: Addison Wesley and Benjamin Cummings.

7. Draper, S.W., \& Brown, M.I. (2004). Increasing interactivity in lectures using an electronic voting system. Journal of Computer Assisted Learning, 20(2), 81-94.
8. Eastman, J. K. (2007). Enhancing Classroom Communication With Interactive Technology: How Faculty Can Get Started. College Teaching Methods \& Styles Journal, 3(1), 31-38.

9. Graham, C. R., Tripp, T. R., Seawright, L., \& Joeckel, G. L. (2007). Empowering or compelling reluctant participators using audience response systems. Active Learning in Higher Education, 8(3), 233-258.

10. iClicker.com (2009). Solutions for Corporate, Government and Nonprofit. Retrieved January 5, 2009 from: http://www.iclicker.com/dnn/SolutionsFor/Corpo rateGovernmentNonprofit/tabid/186/Default.asp $\mathrm{x}$.

11. Jackson, M. H. \& Trees, A. R. (2003). Clicker Implementation and Assessment. Retrieved January $7, \quad 2009$ from http://comm.colorado.edu/mjackson/clickerrepor t.htm.

12. Jones, C. G. (2008). Student Perceptions of the Impact of Web-Based Homework on Course Interaction and Learning in Introductory Accounting. Issues in Information Systems, IX(1), 223-232.

13. Kaleta, R. and Joosten, T. (2007). Student Response Systems: A University of Wisconsin System Study of Clickers. EDUCAUSE Center for Applied Research (ECAR) Research Bulletin, 2007(10), 1-12.

14. MacGeorge, E. L., et al. (2008). Student evaluation of audience response technology in large lecture classes. Educational Technology Research and Development, 56(2), 125-145.

15. Massey, A. P. and Brown, S. A. (2005). It's All Fun and Games ... Until Students Learn. Journal of Information Systems Education, 16(1), 9-14.

16. Nadira, A. H. (2007, May 28). You Raised Them, Now Manage Them. Fortune, 155(10), 38-46.

17. Penuel, W. R., Boscardin, C. K., Masyn, K., \& Crawford, V. M. (2007). Teaching with student response systems in elementary and secondary education settings: A survey study. Educational Technology, Research and Development, 55(4), 315-346.

Roschelle, J., Penuel, W. R. and Abrahamson, L. (2004). The Networked Classroom. Educational Leadership, 61(5), 50-54.

18. Simpson, V. and Oliver, M. (2007). Electronic voting systems for lectures then and now: A comparison of research and practice. Australian 
The Impact of Student Response Systems on Student Behavior and Performance in a Management Information Systems Course

Journal of Educational Technology, 23(2), 187208.

19. Zhu, E. (2008). Teaching with Clickers. Center for Research on Learning and Teaching (CRLT) Occasional Papers, 22, University of Michigan. Retrieved January 5, 2009 from: http://www.crlt.umich.edu/inst/responsesystem.p hp. 
Table 1 - Clicker Survey Results

5-Point Likert Scale (5=Strongly Agree, 4=Agree, 3=Neither, 2=Disagree, 1=Strongly Disagree)

\begin{tabular}{|c|c|c|c|c|c|c|c|}
\hline & \# & Mean & SD & Med & SA/A & $\mathbf{N}$ & D/SD \\
\hline \multicolumn{8}{|l|}{ Student Enjoyment and Interest } \\
\hline I enjoy using the clicker to answer the questions. & 94 & 4.28 & 0.80 & 4 & $83 \%$ & $15 \%$ & $2 \%$ \\
\hline I enjoy reading the questions and possible answers. & 94 & 3.71 & 1.01 & 4 & $55 \%$ & $34 \%$ & $11 \%$ \\
\hline I enjoy seeing the results AFTER each question. & 93 & 4.43 & 0.81 & 5 & $90 \%$ & $8 \%$ & $2 \%$ \\
\hline I enjoy seeing the results DURING a question. & 93 & 3.74 & 1.31 & 4 & $62 \%$ & $20 \%$ & $17 \%$ \\
\hline I enjoy discussing the questions with my classmates. & 93 & 3.55 & 1.02 & 3 & $46 \%$ & $45 \%$ & $9 \%$ \\
\hline I enjoy the opinion polling. & 94 & 3.98 & 1.04 & 4 & $67 \%$ & $29 \%$ & $4 \%$ \\
\hline Clickers increase my interest in the subject material. & 95 & 3.88 & 1.09 & 4 & $67 \%$ & $21 \%$ & $12 \%$ \\
\hline Clickers increase my interest during class sessions. & 94 & 4.20 & 0.95 & 4 & $83 \%$ & $11 \%$ & $6 \%$ \\
\hline \multicolumn{8}{|l|}{ Student Attendance and Participation } \\
\hline Clickers encourage me to attend class. & 94 & 4.02 & 1.14 & 4 & $67 \%$ & $24 \%$ & $9 \%$ \\
\hline Clickers encourage me to be on time for class. & 94 & 3.83 & 1.14 & 4 & $61 \%$ & $27 \%$ & $13 \%$ \\
\hline Clickers encourage me to stay for the entire class. & 96 & 3.92 & 1.09 & 4 & $64 \%$ & $26 \%$ & $9 \%$ \\
\hline Clickers encourage me to listen during lectures. & 96 & 4.12 & 0.95 & 4 & $81 \%$ & $11 \%$ & $7 \%$ \\
\hline The clicker should be used to record attendance. & 96 & 3.48 & 1.56 & 4 & $55 \%$ & $16 \%$ & $29 \%$ \\
\hline Clickers encourage me to participate in discussions. & 94 & 3.54 & 1.05 & 4 & $51 \%$ & $37 \%$ & $12 \%$ \\
\hline Clickers encourage me to ask questions in class. & 96 & 3.09 & 1.04 & 3 & $28 \%$ & $49 \%$ & $23 \%$ \\
\hline Clickers encourage me to take notes during class. & 93 & 3.57 & 1.27 & 4 & $59 \%$ & $20 \%$ & $20 \%$ \\
\hline The clicker should be used for class participation grades. & 96 & 3.92 & 1.25 & 4 & $76 \%$ & $7 \%$ & $17 \%$ \\
\hline \multicolumn{8}{|l|}{ Student Comprehension and Preparation } \\
\hline Clicker questions help me understand the material. & 95 & 4.24 & 0.80 & 4 & $86 \%$ & $9 \%$ & $4 \%$ \\
\hline Discussing with classmates helps me understand the material. & 97 & 3.55 & 0.97 & 4 & $54 \%$ & $33 \%$ & $13 \%$ \\
\hline Clickers encourage me to read the material BEFORE class. & 97 & 2.72 & 1.26 & 3 & $27 \%$ & $27 \%$ & $46 \%$ \\
\hline Clickers encourage me to read the material AFTER class. & 95 & 2.79 & 1.23 & 3 & $26 \%$ & $31 \%$ & $43 \%$ \\
\hline The clicker questions help me prepare for the exams. & 97 & 4.38 & 0.90 & 5 & $84 \%$ & $12 \%$ & $4 \%$ \\
\hline The Study Guides help me prepare for the exams. & 69 & 4.52 & 0.83 & 5 & $84 \%$ & $13 \%$ & $3 \%$ \\
\hline \multicolumn{8}{|l|}{ Clicker Setup and Question Delivery } \\
\hline The registration with the Roll Call was easy to complete. & 85 & 4.57 & 0.63 & 5 & $95 \%$ & $4 \%$ & $1 \%$ \\
\hline The clicker is easy to use for answering the questions. & 87 & 4.85 & 0.45 & 5 & $99 \%$ & $1 \%$ & $0 \%$ \\
\hline I am able to see the clicker questions on the screen. & 89 & 4.88 & 0.37 & 5 & $99 \%$ & $1 \%$ & $0 \%$ \\
\hline I have time to read the questions and choose an answer. & 88 & 4.18 & 0.90 & 4 & $82 \%$ & $13 \%$ & $6 \%$ \\
\hline
\end{tabular}


The Impact of Student Response Systems on Student Behavior and Performance in a Management Information Systems Course

\begin{tabular}{|l|l|l|l|l|l|r|r|}
\hline I am able to understand the clicker questions. & 84 & 4.50 & 0.55 & 5 & $94 \%$ & $3 \%$ & $2 \%$ \\
\hline I would like more clicker questions per class session. & 92 & 3.46 & 1.25 & 4 & $51 \%$ & $28 \%$ & $21 \%$ \\
\hline The clicker should be used for graded quizzes. & 93 & 3.02 & 1.40 & 3 & $42 \%$ & $13 \%$ & $45 \%$ \\
\hline
\end{tabular}

